Article

\title{
Impact of Biohybrid Magnetite Nanoparticles and Moroccan Propolis on Adherence of Methicillin Resistant Strains of Staphylococcus aureus
}

\author{
Soukaina El-Guendouz ${ }^{1,2}$, Smail Aazza ${ }^{1,2}$, Badiaa Lyoussi ${ }^{1}$, Vassya Bankova ${ }^{3}$, João P. Lourenço ${ }^{4,5}$, \\ Ana M. Rosa Costa ${ }^{4}$, José F. Mariano ${ }^{6}$, Maria G. Miguel ${ }^{2, *}$ and Maria L. Faleiro ${ }^{7}$ \\ 1 Laboratory of Physiology-Pharmacology-Environmental Health, Faculty of Sciences Dhar El Mehraz, \\ BP 1796 Atlas, University Sidi Mohamed Ben Abdallah, Fez 30 000, Morocco; \\ soukaina.elguendouz@gmail.com (S.E.G.); aazzasmail@ymail.com (S.A.); lyoussi@gmail.com (B.L.) \\ 2 Department of Chemistry and Pharmacy, Faculty of Science and Technology, University of Algarve, \\ Campus de Gambelas, MeditBio, Faro 8005-139, Portugal \\ 3 Institute of Organic Chemistry with Centre of Phytochemistry, Acad. G. Bonchev strl. bl. 9, Sofia 1113, \\ Bulgaria; bankova@orgchm.bas.bg \\ 4 Algarve Chemistry Research Centre(CIQA) and Department of Chemistry and Pharmacy, \\ Faculty of Science and Technology, University of Algarve, Faro 8005-139, Portugal; jlouren@ualg.pt (J.P.L.); \\ amcosta@ualg.pt (A.M.R.C.) \\ 5 CQE, Centro de Química Estrutural, Instituto Superior Técnico, University of Lisbon, Av. Rovisco Pais, \\ Lisboa 1049-001, Portugal \\ 6 Department of Physics and CeFEMA, Faculty of Science and Technology, University of Algarve, \\ Campus de Gambelas, Faro 8005-139, Portugal; jmariano@ualg.pt \\ 7 Department of Biological Sciences and Bioengineering, Faculty of Science and Technology, \\ University of Algarve, Center for Biomedical Research, Faro 8005-139, Portugal; mfaleiro@ualg.pt \\ * Correspondence: mgmiguel@ualg.pt; Tel.: +35-128-980-0100
}

Academic Editor: Derek J. McPhee

Received: 21 July 2016; Accepted: 2 September 2016; Published: 9 September 2016

\begin{abstract}
Biofilm bacteria are more resistant to antibiotics than planktonic cells. Propolis possesses antimicrobial activity. Generally, nanoparticles containing heavy metals possess antimicrobial and antibiofilm properties. In this study, the ability of adherence of Methicillin Resistant Strains of Staphylococcus aureus (MRSA) to catheters treated with magnetite nanoparticles (MNPs), produced by three methods and functionalized with oleic acid and a hydro-alcoholic extract of propolis from Morocco, was evaluated. The chemical composition of propolis was established by gas chromatography mass spectrometry (GC-MS), and the fabricated nanostructures characterized by X-ray diffraction (XRD), transmission electron microscopy (TEM), Mossbauer spectroscopy and Fourrier transform infrared spectroscopy (FTIR). The capacity for impairing biofilm formation was dependent on the strain, as well as on the mode of production of MNPs. The co-precipitation method of MNPs fabrication using $\mathrm{Fe}^{3+}$ and $\mathrm{Na}_{2} \mathrm{SO}_{3}$ solution and functionalized with oleic acid and propolis was the most effective in the impairment of adherence of all MRSA strains to catheters $(p<0.001)$. The adherence of the strain MRSA16 was also significantly lower $(p<0.001)$ when the catheters were treated with the hybrid MNPs with oleic acid produced by a hydrothermal method. The anti-MRSA observed can be attributed to the presence of benzyl caffeate, pinocembrin, galangin, and isocupressic acid in propolis extract, along with MNPs. However, for MRSA16, the impairment of its adherence on catheters may only be attributed to the hybrid MNPs with oleic acid, since very small amount, if any at all of propolis compounds were added to the MNPs.
\end{abstract}

Keywords: co-precipitation; hydrothermal; functionalization; propolis; flavonoids; diterpenes 


\section{Introduction}

Propolis is a natural resinous substance collected by honeybees from parts of plants, buds, and exudates, mixed with bees wax and salivary enzymes. Propolis is mainly constituted by resin $(50 \%)$, wax $(30 \%)$, essential oils $(10 \%)$, pollen $(5 \%)$, and other substances $(5 \%)$, such as debris, minerals and organic compounds, despite the chemical variability that can be found. Such differences can be attributed to the different plants from where bees can collect the materials, as well as the different harvesting seasons of propolis. Polyphenols, terpenoids including steroids, naphthalene and stilbene derivatives, and fatty acids are some examples of organic compounds that can be found in propolis [1,2]. Different biological properties have been attributed to propolis, such as antimicrobial, anti-inflammatory, antioxidant, antidiabetic, spasmolytic, anaesthetic, anticancer, and immunomodulatory effects [2,3].

Staphylococcus aureus is a Gram-positive bacterium that mainly colonizes the nares and is considered a human pathogen that shows increasing incidence in patients with prolonged hospitalization, submitted to intravenous drugs or under treatment with enteral feedings or dialysis, in postoperative surgical wounds in decubitus ulcers or in indwelling catheters [4-6]. Its incidence is increasing also in the community [7]. Over time, Staphylococcus aureus has developed resistance to several antibiotics and, presently, methicillin resistant strains (MRSA) are causing serious infections in hospitals or even in the community [8,9]. For these reasons, alternative approaches are required to fight this bacterial pathogen, and one of them is the use of natural products. Propolis comes as a natural candidate due to its multidirectional mechanism of action on bacterial cells, which renders the development of resistance unlikely [10]. The utilization of propolis extracts has already been assayed as anti-MRSA agents, as is shown in Table 1, which compiles the results of several authors who observed anti-MRSA activity in propolis of diverse origins.

Biofilm bacteria (adherent bacterial cells) are more resistant to antibiotics, cleaning and eradication than planktonic cells (cells in suspension). The percentage of infections associated with biofilm formation in medical devices is more than $25 \%$. These infections cause great mortality and morbidity rates in patients with indwelling or implanted devices, with the consequent increasing of costs due to the long term treatments [11].

Different types of nanoparticles have been reported as possessing antimicrobial and antibiofilm properties, particularly those containing heavy metals [12]. Iron oxide magnetic nanoparticles were approved by FDA for biomedical uses, because they occur naturally in liver, spleen and human heart, consequently, they will be non-toxic and biocompatible at physiological concentrations. In addition, the production of these nanoparticles is not difficult and they are chemically stable under physiological conditions. They are also easily functionalized. Functionalized iron oxide magnetic nanoparticles, such as magnetite nanoparticles (MNPs) have been evaluated for inhibiting microbial growth and biofilm formation of yeasts (Candida albicans, C. tropicalis, C. krusei, C. glabrata, and Saccharomyces cerevisiae), and bacteria (Escherichia coli, Staphylococcus aureus, Pseudomonas aeruginosa, and Enterococcus faecalis) [13].

The majority of the methods used for synthesizing stable, biocompatible and monodispersed MNPs include co-precipitation, thermal decomposition, hydrothermal synthesis, microemulsion, and sonochemical synthesis. However, other methods have been developed and reported: electrochemical synthesis, laser pyrolysis techniques, and microorganism or bacterial synthesis [14]. In order to prevent that MNPs form aggregates, and for raising its biocompatibility, stability and biological application, such NPs may be functionalized with some biomolecules [14]. Oleic acid has been used alone or along with natural products for preventing biofilm formation of pathogenic microorganisms (C. albicans, C. tropicalis, S. aureus, and E. coli) or for promoting its disruption $[12,15,16]$.

The main goal of the present work was to evaluate the ability of a hybrid nanosystem constituted by magnetite nanoparticles, produced by three methods based on two methods (co-precipitation and hydrothermal synthesis) and functionalized with oleic acid and a hydro-alcoholic extract of propolis from Morocco to prevent the adherence of MRSA strains on catheters, and therefore impair the formation of biofilm. 
Table 1. Utilization of propolis extracts as anti-Methicillin Resistant Strains of Staphylococcus aureus (anti-MRSA) agents.

\begin{tabular}{|c|c|c|c|c|c|}
\hline Sample & Sample Extraction/Compounds & Strains & $\operatorname{MIC}^{*}(\mathrm{mg} / \mathrm{mL}) ; \mathrm{MBC}^{* *}(\mathrm{mg} / \mathrm{mL})$ & Major Compounds & Ref. \\
\hline \multirow{8}{*}{$\begin{array}{l}\text { Twenty-four batches of } \\
\text { propolis collected over two } \\
\text { years (2010 and 2011) from } \\
\text { different places in France }\end{array}$} & 1. Methanol $(\mathrm{MeOH})$ & $\begin{array}{l}\text { Six human pathogenic bacterial } \\
\text { strains collected by the Laboratory } \\
\text { of Bacteriology at the University } \\
\text { Hospital, Center of Angers, France) }\end{array}$ & $0.090 \rightarrow 0.100 ;-$ & $\begin{array}{l}\text { Pinobanksin-3-acetate, pinocembrin, chrysin, galangin, } \\
\text { prenyl caffeate }\end{array}$ & [17] \\
\hline & 2. Dichloromethane (DCM) & The same reported above & $0.057-0.097 ;-$ & The same reported above & \\
\hline & 3. Mixture of $\mathrm{DCM}, \mathrm{MeOH}, \mathrm{H}_{2} \mathrm{O}(31 / 19 / 4)$ & The same reported above & $\begin{array}{l}0.030 \\
>0.100\end{array}$ & The same reported above & \\
\hline & Pinobanksin-3-acetate & $\begin{array}{l}\text { MRSA (0706C0025) } \\
\text { MRSA (0702E0196) }\end{array}$ & $\begin{array}{l}>0.100 ;- \\
>0.100 ;-\end{array}$ & & \\
\hline & Pinocembrin & $\begin{array}{l}\text { MRSA (0706C0025) } \\
\text { MRSA (0702E0196) }\end{array}$ & $\begin{array}{l}>0.100 ;- \\
>0.100 ;-\end{array}$ & & \\
\hline & Chrysin & $\begin{array}{l}\text { MRSA (0706C0025) } \\
\text { MRSA (0702E0196) }\end{array}$ & $\begin{array}{l}>0.100 ;- \\
>0.100 ;-\end{array}$ & & \\
\hline & Galangin & $\begin{array}{l}\text { MRSA (0706C0025) } \\
\text { MRSA (0702E0196) }\end{array}$ & $\begin{array}{l}>0.100 ;- \\
>0.100 ;-\end{array}$ & & \\
\hline & Prenyl caffeate & $\begin{array}{l}\text { MRSA (0706C0025) } \\
\text { MRSA (0702E0196) }\end{array}$ & $\begin{array}{l}0.070 ;- \\
0.070 ;-\end{array}$ & & \\
\hline $\begin{array}{l}\text { Propolis, collected at } \\
\text { Moravia, Czech Republic }\end{array}$ & $\begin{array}{l}\text { Special propolis extract GH2002 (see the } \\
\text { reference for the extraction method) }\end{array}$ & Ten strains & $\begin{array}{l}0.13-0.25 ; \\
0.5-1\end{array}$ & - & [18] \\
\hline $\begin{array}{l}\text { Propolis samples from } \\
\text { an apiary in Kamianna } \\
\text { near Nowy Sacz in } \\
\text { Southern Poland }\end{array}$ & Hydro-alcoholic $(70 \%)$ extract of propolis & $\begin{array}{l}\text { Five strains from blood } \\
\text { clinical origin } \\
\text { MRSA ATCC } 43300\end{array}$ & $\begin{array}{l}0.39-0.78 \\
0.78-3.13 \\
0.78 ; 3.13\end{array}$ & $\begin{array}{l}\text { Pinocembrin, kaempferol, galangin, chrysin, apigenin, } \\
\text { quercetin, gallic acid, ferullic acid, caffeic acid, caffeic acid } \\
\text { phenethyl ester, } p \text {-coumaric acid and cinnamic acid }\end{array}$ & [10] \\
\hline $\begin{array}{l}\text { The crude propolis and } \\
\text { their respective ethanol } \\
\text { extracts were sourced from } \\
\text { the city of União da Vitória, } \\
\text {-State of Paraná, Brazil, } \\
\text { provided by Novo Mel }\end{array}$ & Ethanol extracts & $\begin{array}{l}\text { Strains (clinical isolate) were } \\
\text { obtained from the Bacterial Library } \\
\text { of the Microbiology Laboratory, } \\
\text { Department of Pathology, Santa } \\
\text { Casa de São Paulo, -School of } \\
\text { Medical Sciences }\end{array}$ & 1.42 & $\begin{array}{l}\text { 3-[4-Hydroxy-3-(oxobutyl)-phenylacrylic acid; } \\
\text { 3-prenyl-3(E)-(4-hydroxy-3-methyl-2-butenol)-5-prenylcinnamic } \\
\text { acid; 3-prenyl-4-(2-methylpropionyloxi)cinnamic acid; } \\
\text { 3-prenyl-4-dihydrocynamoiloxi-cinnamic acid; } \\
\text { dihydrokaemferide; 3-prenyl-4-hydroxycinnamic acid, caffeic } \\
\text { acid; caffeoylquinic acid 1; caffeoylquinic acid 2; caffeoylquinic } \\
\text { acid 3; caffeoylquinic acid 4; caffeoylquinic acid 5; cinnamic } \\
\text { acid; } \text {-coumaric acid; kaempferide; kaempferol; betuletol; } \\
\text { 2,2-dimethyl-6-carboxyethenyl-2H-1-benzopirane; } \\
\text { 2,2-dimethyl-8-prenyl-2H-1-benzopirano-6-propenoic acid; } \\
\text { (E)-3-44-hydroxy-3-[(E)-4-(2,3)-dihydrocynamoiloxi-3-methyl- } \\
\text { 2-butenyl]-5-renylphenyl-2-propenoic acid; } \\
\text { 3,4-dihydroxy-5-prenyl-cinnamic acid; } \\
\text { 3,5-diprenyl-4-hydroxy-cinnamic acid }\end{array}$ & [19] \\
\hline
\end{tabular}


Table 1. Cont.

\begin{tabular}{|c|c|c|c|c|c|}
\hline Sample & Sample Extraction/Compounds & Strains & MIC * (mg/mL); MBC ** $(\mathrm{mg} / \mathrm{mL})$ & Major Compounds & Ref. \\
\hline \multirow{3}{*}{$\begin{array}{l}\text { Two Jordanian propolis } \\
\text { samples from two locations: } \\
\text { University of Jordan } \\
\text { (Type I), and Al-Hashmeah } \\
\text { (Type II) }\end{array}$} & $\begin{array}{l}\text { Type I crude aqueous methanol extracts } \\
\text { Type II crude aqueous methanol extracts } \\
\text { Pinobanksin-3-O-acetate Pinocembrin }\end{array}$ & $\begin{array}{l}\text { MRSA isolated from hospitalized } \\
\text { patients at the Jordan University }\end{array}$ & 4.69 & - & \multirow{3}{*}{20} \\
\hline & Type II crude aqueous methanol extracts & The same reported above & 18.75 & & \\
\hline & Pinobanksin-3-O-acetate Pinocembrin & & $\begin{array}{l}0.25 ; \\
0.25\end{array}$ & & \\
\hline $\begin{array}{l}\text { The propolis was from } \\
\text { Guadalcanal Province } \\
\text { (The Solomon Islands) for } \\
\text { BeeVital \& Herbal } \\
\text { Apothecary (Withby, UK) } \\
\text { 'Pacific propolis' }\end{array}$ & $\begin{array}{l}\text { Propolis extracted with } 95 \% \text { ethyl alcohol } \\
(\text { EEP). A portion of EEP suspended in } \\
\text { water/ethanol (10/1) was partitioned } \\
\text { between } n \text {-hexane (HEX), ethyl acetate (EA), } \\
n \text {-BuOH (BUT) and water (WAT). EA (1-16) } \\
\text { fractions obtained from EA fractionated by } \\
\text { gel fi ltration using Sephadex }{ }^{\circledR} \text { LH-20-100 }\end{array}$ & $\begin{array}{l}\text { One hundred and twenty clinical } \\
\text { MRSA isolates were collected from } \\
\text { the clinical laboratories of the New } \\
\text { Royal Infirmary (Edinburgh, UK) }\end{array}$ & $\begin{array}{l}\text { EEP: } 0.064-0.128 ;- \\
\text { HEX: } 0.512 ;- \\
\text { EA: } 0.064-0.128 \\
\text { BUT: } 0.128-0.256 \\
\text { WAT: }: 0.512 \\
\text { EA 9-EA 15: } 0.016-0.064\end{array}$ & $\begin{array}{l}\text { Prenylflavanones: propolin } \mathrm{H} \text {, propolin } \mathrm{G} \text {, propolin } \mathrm{D} \text {, } \\
\text { propolin C }\end{array}$ & [21] \\
\hline $\begin{array}{l}\text { Purchased as } \\
\text { ethanolic extract }\end{array}$ & $\begin{array}{l}\text { Ethanolic extract of propolis (P8904, EEP, } \\
\text { pH 7.3, Sigma, St. Louis, MO, USA) }\end{array}$ & MRSA (ATCC 33591) & $\begin{array}{l}1.024 ;- \\
\text { Propolis plus mupirocin for } \\
\text { treating nares of the rabbits } \\
\text { infected by MRSA resulted in more } \\
\text { profound reduction in bacterial cell } \\
\text { count and inflammatory response } \\
\text { compared with the rest of the } \\
\text { treatment modalities without } \\
\text { this conjugation }\end{array}$ & - & [22] \\
\hline $\begin{array}{l}\text { Three samples of propolis } \\
\text { were obtained from Croatia: } \\
\text { sample } 5587 \text { (Zagreb) and } \\
\text { samples } 5582 \text { and } \\
5581 \text { (Imotski) }\end{array}$ & $\begin{array}{l}\text { Hydro-alcoholic extract }(80 \%) \text { of propolis } \\
\text { (EEP), Galangin }\end{array}$ & Ten strains of MRSA & $\begin{array}{l}\text { Sample 5587: } 1.06 ; 2.00 \\
\text { Sample 5582: } 4.98 ; 9.37 \\
\text { Sample 5581: } 1.19 ; 2.37 \\
\text { Galangin: } 0.16 ; 0.27\end{array}$ & Flavones, flavonols, flavanones, galangin & [23] \\
\hline
\end{tabular}

* MIC: Minimal Inhibitory Concentration; ${ }^{* *}$ MBC: Minimum Bactericidal Concentration; -: not referred by the authors. 
Table 2. Chemical composition of hydro-alcoholic extract of Moroccan propolis.

\begin{tabular}{|c|c|c|c|c|c|c|c|c|c|c|c|}
\hline Aromatic Acids & $\%$ & Phenolic Acid Esters & $\%$ & Flavonoids & $\%$ & Diterpenes & $\%$ & $\begin{array}{c}\text { Sugars and } \\
\text { Sugar Derivatives }\end{array}$ & $\%$ & Fatty Acids & $\%$ \\
\hline Benzoic acid & 0.4 & Pentenyl $p$-coumarate & 0.7 & Pinostrobin chalcone & 2.7 & Ferruginol & 1.2 & Monosaccharides & 0.4 & Hexadecanoic acid & - \\
\hline Hidroxybenzoic acid & 0.1 & Isopentenyl caffeate & 1.8 & Pinocembrin chalcone & 5.9 & Communic acid & 2.7 & Disaccharides & - & Octadecanoic acid & 1.0 \\
\hline Cinnamic acid & 0.3 & Pentenyl caffeate & 0.9 & Pinocembrin & 7.4 & Totarol & 1.1 & Glycerol & 0.1 & Octadecenoic acid & 0.5 \\
\hline$p$-Coumaric acid & 0.3 & Dimethylallyl caffeate & 1.2 & Pinobanksin & 3.6 & Imbricataloic acid & 3.2 & Inositol & $\operatorname{Tr}$ & Tetracosanoic acid & - \\
\hline Dimethoxycinnamic acid & 0.6 & Pentenyl ferulate & 0.9 & $\begin{array}{l}\text { Pinobanksin } \\
\text { 3-O-acetate }\end{array}$ & 3.4 & 13-epi-Cupressic acid & 2.2 & Total & 0.5 & Total & 1.5 \\
\hline Ferulic acid & 0.4 & Benzyl ferulate & 1.7 & Galangin & 5.3 & Ferruginolon & 1.2 & & & & \\
\hline Isoferulic acid & 0.4 & Benzyl $p$-coumarate & 1.3 & Chrysin & 3.6 & Dehydroabietic acid & $\mathrm{Tr}$ & & & & \\
\hline Caffeic acid & 0.8 & Benzyl caffeate & 4.7 & Total & 31.9 & Isocupressic acid & 8.1 & & & & \\
\hline \multirow[t]{5}{*}{ Total } & 3.3 & $\begin{array}{c}\text { Caffeic acid } \\
\text { phenetyl ester }\end{array}$ & 1.7 & & & Junicedric acid & 1.8 & & & & \\
\hline & & Cinnamyl ferulate & 0.4 & & & Total & 21.5 & & & & \\
\hline & & Cinnamyl caffeate & 1.2 & & & & & & & & \\
\hline & & Total & 16.5 & & & & & & & & \\
\hline & & & tanda & d deviation does not suc & eed $6 \%$ & for any of the constitu & & & & & \\
\hline
\end{tabular}




\section{Results}

\subsection{Chemical Composition of Propolis Extract}

Table 2 depicts the chemical composition of the hydro-alcoholic extract of propolis. Flavonoids $(31.9 \%)$, diterpenes $(21.5 \%)$, and phenolic acid esters $(16.5 \%)$ were the main groups of compounds found in this extract. Only four components were present at concentrations higher than 5\%: the diterpene isocupressic acid (8.1\%) (1), and the three flavonoids pinocembrin (7.4\%) (2), pinocembrin chalcone $(5.9 \%)(3)$, and galangin (5.3\%) (4). The phenolic acid ester benzyl caffeate (4.7\%) (5) was present in the extract at a concentration very close to $5 \%$ (Table 2 ).

\subsection{Characterization of the Nanomaterial}

\subsubsection{X-ray diffraction $(\mathrm{XRD})$}

Figure 1 displays the XRD patterns of the non-functionalized nanoparticles synthesized by each of the three methods. The diffraction peaks present in the patterns of all the samples indicate magnetite as the sole crystalline phase. The smaller width of the peaks in the pattern of Method \#2 suggests a larger size of the nanoparticles in that sample, in agreement with transmission electron microscopy (TEM) observations. Figure 2 represents the diffractograms of both functionalized and nonfunctionalized nanoparticles, synthesized by Method \#1, where it is evident that the functionalization procedure does not change the structure and composition of the nanoparticles.

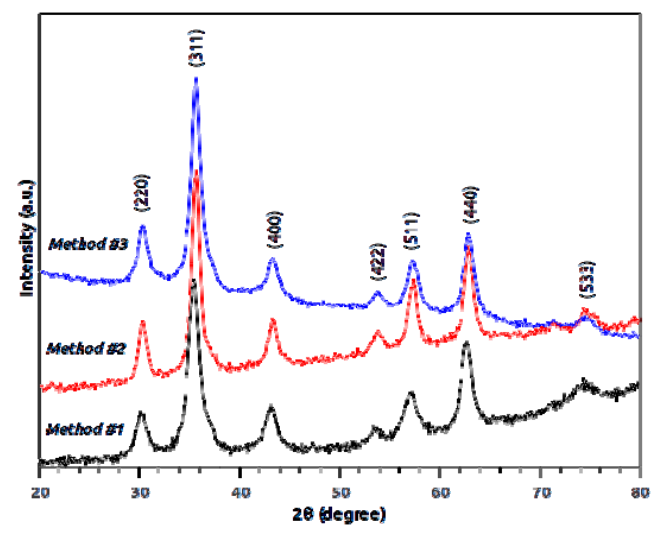

Figure 1. X-ray diffractograms of magnetite nanoparticles synthesized by the three methods. The labeled crystallographic planes refer to magnetite.

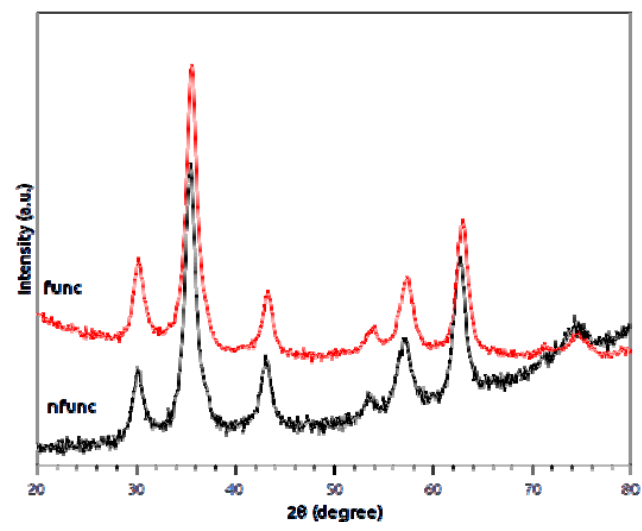

Figure 2. X-ray diffractograms of nonfunctionalized (nfunc) and functionalized with oleic acid (funct) magnetite nanoparticles, synthesized using Method \#1. 


\subsubsection{TEM}

This analysis was used to characterize the morphology of the nonfunctionalized nanoparticles and the results are presented in Figure 3. The images show that the three methods produced roughly spherical nanoparticles, although those produced by Method \#2 are of more regular shape, with diameters of about $15 \mathrm{~nm}$, while Method \#1 originates more angular shaped nanoparticles, with estimated sizes of $10 \mathrm{~nm}$ and Method \#3 produces nanoparticles with approximately the same size but with a more regular spherical shape.

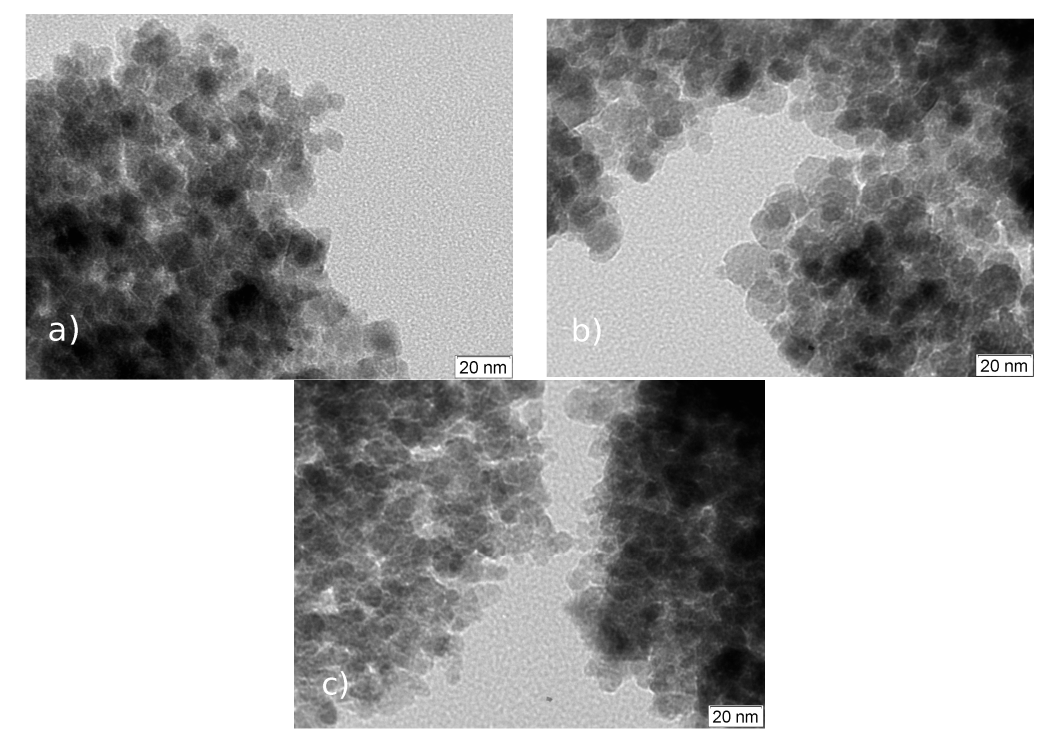

Figure 3. TEM micrographs of the nonfunctionalized nanoparticles synthezised by Methods: \#1 (a); $\# 2$ (b); and \#3 (c).

\subsubsection{Mössbauer Spectroscopy}

In order to investigate the possible alteration of structure and composition by the functionalization procedure, two samples of magnetite synthesized by Method \#1, with and without functionalization with oleic acid, were subject to Mössbauer analysis. Figure 4 shows the ${ }^{57} \mathrm{Fe}$ Mössbauer spectra of these samples. As can be seen, no apparent alteration on the spectra was introduced by the functionalization of the nanoparticles, which agrees with the XRD results.

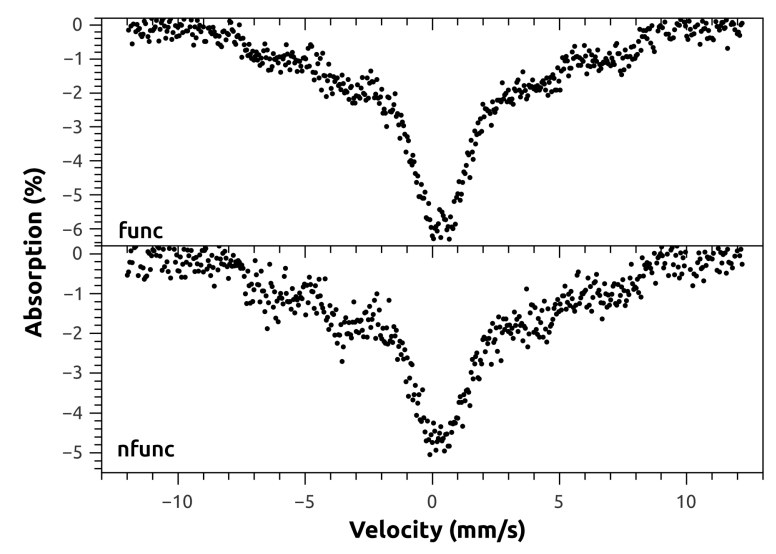

Figure 4. Room temperature ${ }^{57} \mathrm{Fe}$ Mössbauer spectra of magnetite nanoparticles, nonfunctionalized and functionalized with oleic acid, synthesized by Method \#1. The acquisition time is different for the two spectra. 
To further investigate the structure and composition of the as-synthesized MNPs, one sample of uncoated MNP synthesized by each of the three methods was analyzed by transmission Mössbauer spectroscopy. The recorded spectra are shown in Figure 5. The room temperature spectra show the gradual passage from bulk-like to superparamagnetic (SPM) behavior, as the average size of the particles decrease. The Method \#2 spectra displays a single sextet compatible with magnetite, with board lines indicating that these particles have a multidomain structure, although close to the single domain size limit. In the Method \#3 sample, the central doublet evidences a predominant SPM size, with some contribution from the non-SPM particles sextet, correlating to a size distribution with smaller average particle size. Sample from Method \#1 exhibits a similar behavior. Thus, it can be stated from the Mössbauer analysis that Method \#2 produces $\mathrm{Fe}_{3} \mathrm{O}_{4} \mathrm{NPs}$ that have on average a larger size than those produced by Methods \#1 and \#3, which is in good agreement with the results of both TEM and XRD.

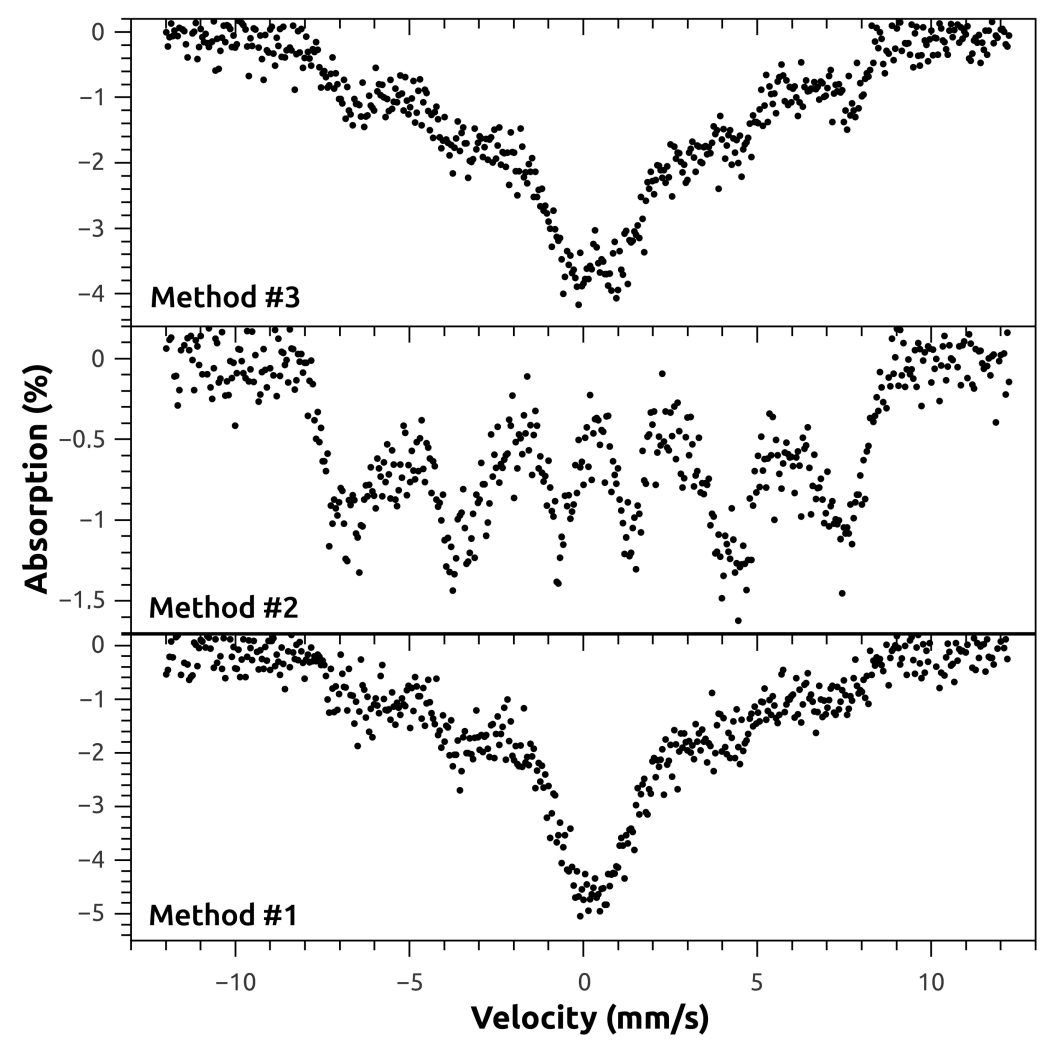

Figure 5. Room temperature ${ }^{57} \mathrm{Fe}$ Mössbauer spectra of the nonfunctionalized iron oxide nanoparticles synthesized by the tree different methods. The spectra were taken with different acquisition times.

\subsubsection{Fourrier Tranform Infrared Spectroscopy (FTIR)}

In the FTIR spectra of MNPs prepared by Methods \#1 and \#2 (Figure 6A,B), an intense band near $600 \mathrm{~cm}^{-1}$ and the one centered at $447 \mathrm{~cm}^{-1}$ were observed. A splitting of the former into two bands (approximately 590 and $640 \mathrm{~cm}^{-1}$ ) was observed. Besides these bands, two other are observed in these spectra: one centered near $3445 \mathrm{~cm}^{-1}$ and the other around $1640 \mathrm{~cm}^{-1}$.

The FTIR spectrum of MNPs prepared by Method \#3 (Figure 6C) does not differ much from the former, as the only significant absorption band of dehydroascorbic acid, the oxidation product of ascorbic acid, is from the carbonyl groups, at $1680 \mathrm{~cm}^{-1}$. As a consequence, only a broadening of the $1640 \mathrm{~cm}^{-1}$ band relative to the other NPs samples is observed. Apart from that, two inconspicuous bands, due to C-H asymmetric and symmetric stretching, may be denoted at nearly 2930 and $2850 \mathrm{~cm}^{-1}$, respectively. 


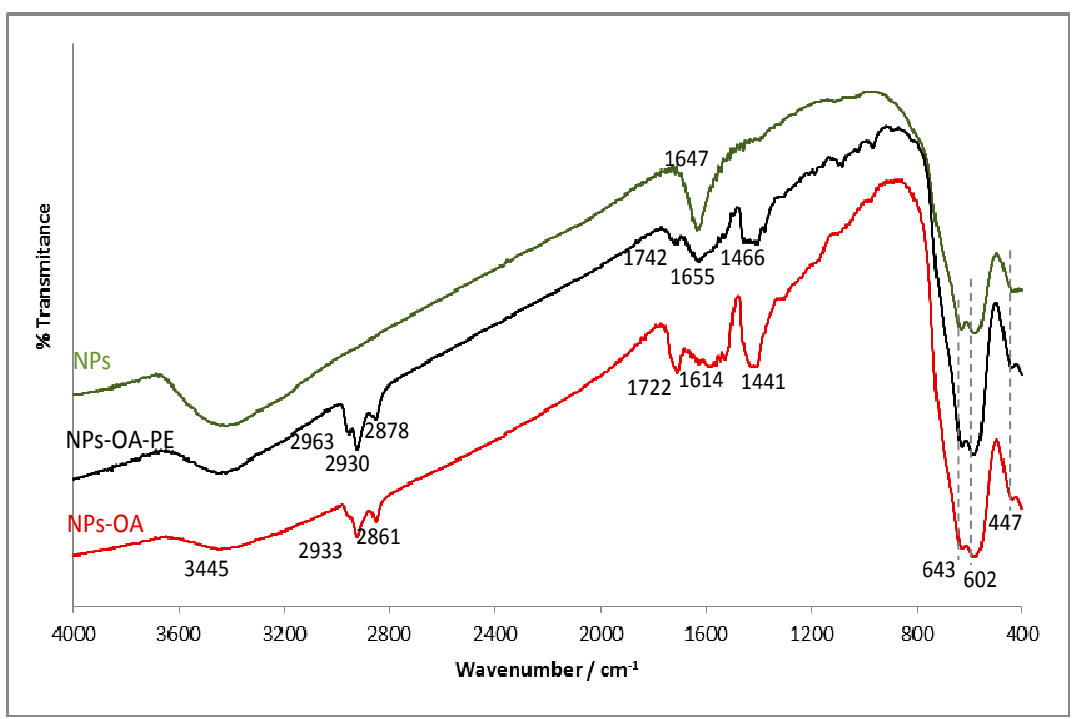

(A)

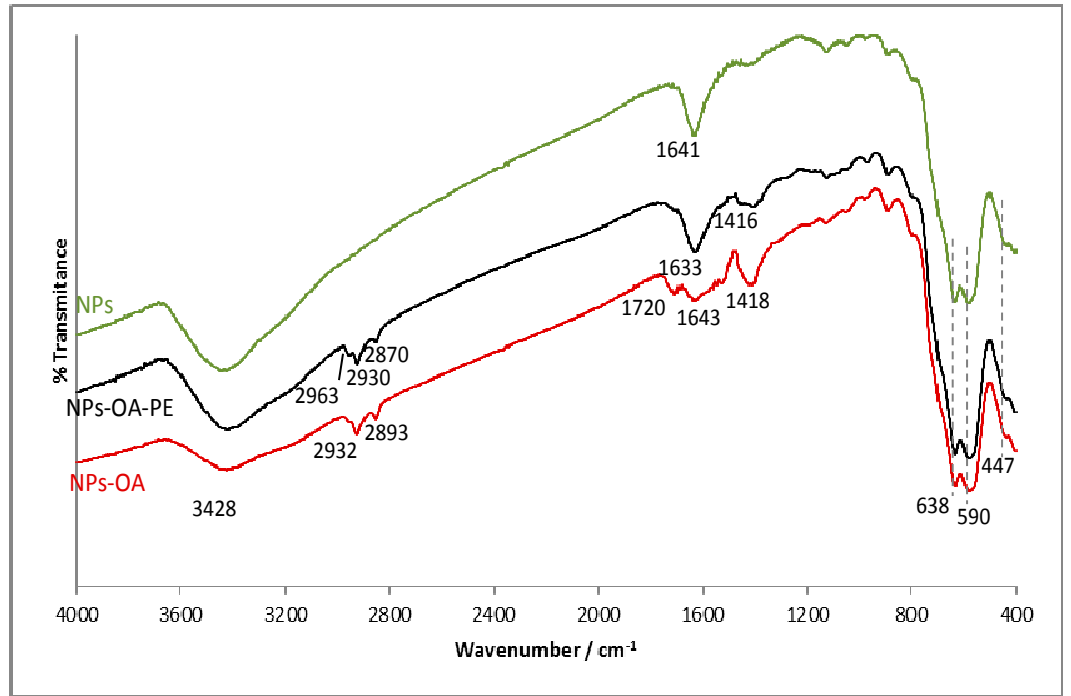

(B)

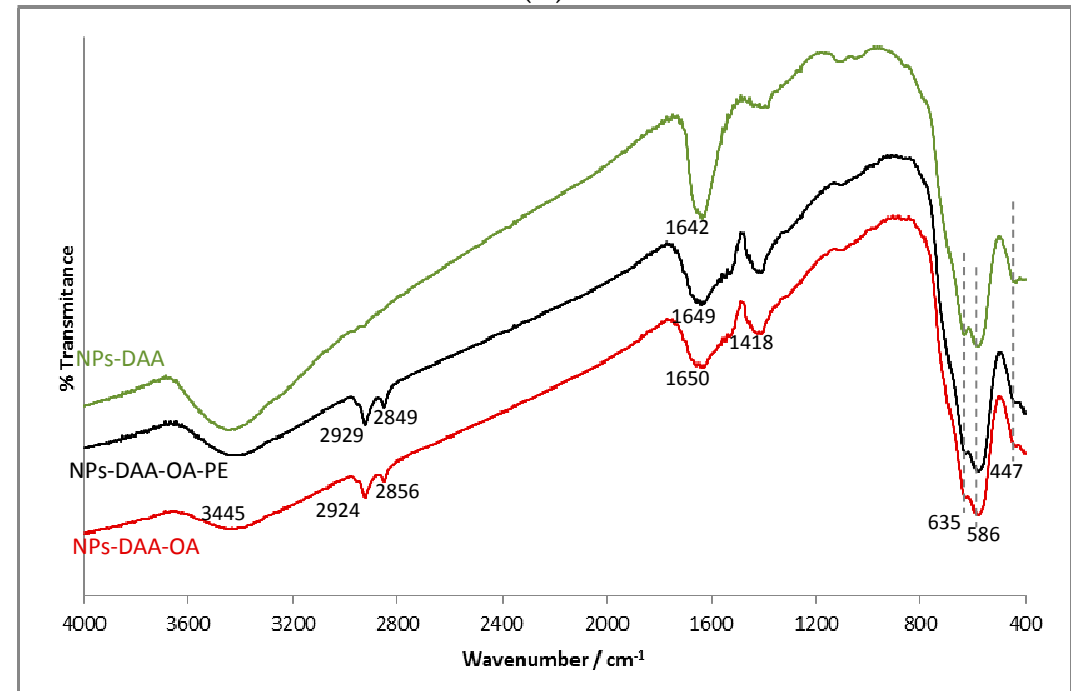

(C)

Figure 6. FTIR spectra of as obtained and functionalized magnetite NPs by: (A) Method \#1; (B) Method \$2; and (C) Method \$3. OA—oleic acid, PE—propolis extract, DAA—dehydroascorbic acid. 
Upon functionalization with oleic acid, the spectra of all MNPs show changes, indicating the presence of the fatty acid: the appearance of the $\mathrm{C}-\mathrm{H}$ asymmetric and symmetric stretching bands, near 2930 and $2870 \mathrm{~cm}^{-1}$, a broadening of the band at $1640 \mathrm{~cm}^{-1}$, and a new band centered around $1430 \mathrm{~cm}^{-1}$, due to the bending of the methylene groups in OA chain. The broadening of the $1640 \mathrm{~cm}^{-1}$ band is due to a shift in the $\mathrm{C}=\mathrm{O}$ stretching band, originally near $1710 \mathrm{~cm}^{-1}$, to lower wavenumbers, upon binding to the surface, that weakens the double bond character of the carbonyl. Nevertheless, in some samples (MNPs obtained by Methods \#1 and \#2), a band at $1720 \mathrm{~cm}^{-1}$ was still visible. After addition of propolis extract, this band remains in the first sample, although less intense, but disappears or at least fades away in the second one. In MNPs prepared by Method \#3 this band is not present, meaning that the presence of dehydroascorbic acid somehow prevented the formation of an oleic acid bilayer, in the same manner as the compounds present in the propolis extract, that seem to decrease the amount of unbound oleic acid.

The effect of the addition of propolis extract on the FTIR spectra is mainly related to the aromatic compounds, since the aliphatic ones, acids, and esters absorb in the same regions as the compounds already present. Therefore, only a new band at $2963 \mathrm{~cm}^{-1}$, attributable to the C-H stretching of unsaturated and aromatic hydrocarbons, as well as a broadening in the band centered near $1430 \mathrm{~cm}^{-1}$, due to the $C=C$ stretching absorption (in the region $1450-1470 \mathrm{~cm}^{-1}$ ) are noteworthy in the spectra of the two first samples. In the last one, the spectra before and after addition of propolis extract seem practically superimposable, which means that only a very small amount, if any at all, of propolis compounds were added to the MNPs.

\subsection{Impact of the Nanoparticles on Bacterial Adherence}

The effect of the nanoparticles on bacterial adherence was evaluated using catheters treated with different MNPs. The results are illustrated in Figure 7A-C. The percentage of adherence of the cells of the MSSA strain was not affected by Methods \#2 and \#3 of nanoparticles production in comparison to the MRSA strains. However, the adherence of this strain was significantly lower $(p<0.05)$ by Method \#1, particularly in the presence of propolis $(p<0.001)$.

The impact of the nanoparticles against the adherence ability of MRSA strains was dependent of the method of production of the nanoparticles and the strain, being the Method \#2 the more efficient in inhibiting adherence of MRSA strains, particularly MRSA 15, which adherence was significantly lower $(p<0.001)$ when the catheters were treated with MNPs functionalized with oleic acid and propolis extract $(50.67 \% \pm 2.90 \%)$. The adherence of MRSA 2 was also impaired by the nanoparticles produced by the Method \#2 $(p<0.001)$. The adherence of the strain MRSA 16 was significantly lower $(p<0.001)$ when the catheters were treated with magnetite nanoparticles produced by Method \#3 either just with oleic acid or nanoparticles with oleic acid and propolis extract.

Thus, in order to impair the adherence of MRSA strains, the use MNPs produced by the Method \#2 and functionalized with oleic acid or oleic acid plus propolis extract are the more appropriate followed by the Method \#3. To our best knowledge, this is the first study that shows that catheters treated with magnetite nanoparticles functionalized with oleic acid and Moroccan propolis can impair the adherence of such problematic pathogenic bacteria, as MRSA strains.

\section{Discussion}

The presence of diterpenes is common in propolis of Mediterranean origin [24]. This group of compounds was already reported in some Moroccan propolis [25]. Popova et al. [25] found at least three main types of propolis of Moroccan origin: flavonoid/phenolic acid esters-type, flavonoid-type, and diterpene-type. In the present work, flavonoid/diterpene-type, along with a relative high amount of phenolic acid esters, was found.

The characterization of the nanomaterials was followed by XRD, TEM, Mössbauer spectroscopy, and FTIR. The diffraction peaks present in the patterns of all the samples indicate magnetite as the sole crystalline phase [26] (ICDD PDF-2 card \#01-071-6337). As reported by Mahdavi et al. [27] for 
functionalized MNPs with oleic acid, XRD data showed negligible effects of this fatty acid on the XRD spectra data. The morphology and particle size of nanoparticles were similar to those reported by Anghel et al. [15] for functionalized magnetite $\left(\mathrm{Fe}_{3} \mathrm{O}_{4} / \mathrm{C}_{18}\right)$, that is, the same type of functionalization (oleic acid) done in the present work. In the Mössbauer spectroscopy, and at room temperature, spectra showed a gradual passage from bulk-like to superparamagnetic (SPM) behavior, as the average size of the particles decrease, a striking characteristic of the superparamagnetic nature of nanoparticles [28].
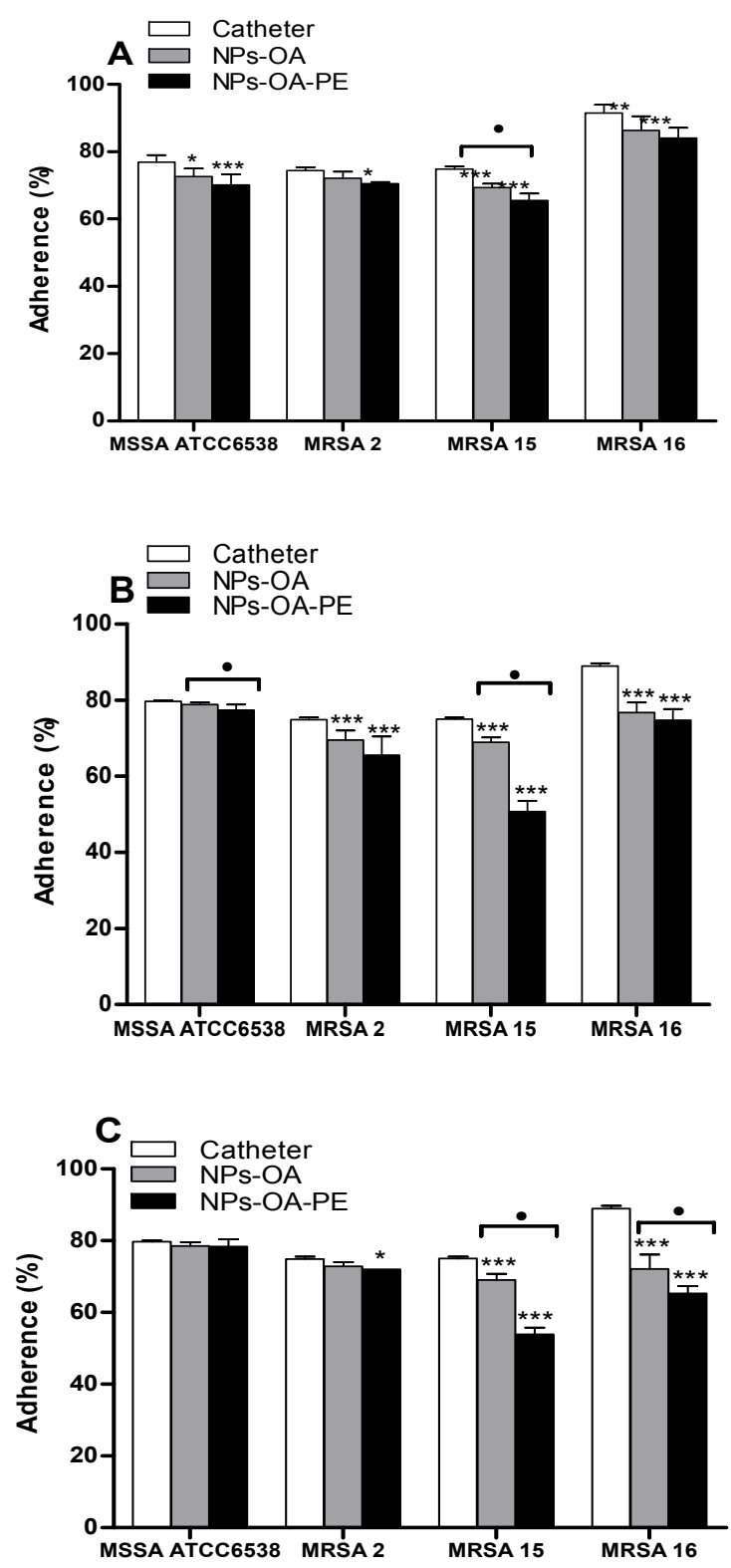

Figure 7. Percentage of adherence of microorganisms on catheter after contact with functionalized MNPs obtained by different methods: (A) Method \#1; (B) Method \#2; and (C) Method \$3. OA—oleic acid, PE-propolis extract, Data represent the mean \pm S.D from two separated experiments, ${ }^{*} p<0.05$; ${ }^{* *} p<0.01 ; * * * p<0.001(n=6)$, statistically significant when compared with catheter not submitted to any treatment. Square brackets indicate the use of One Way ANOVA for each group. $\bullet p 0.05(n=6)$.

FTIR spectroscopy contributes to provide a fast way of identification of MNPs. This technology is also useful when there is their functionalization, because it allows verifying the occurrence of such functionalization. In the identification of the nanoparticles, and for the Methods \#1 and \#2 there was confirmation of the presence of MNPs due to the intense band near $600 \mathrm{~cm}^{-1}$, attributed to the 
stretching of the Fe-O bond of octahedral positions, and the one centered at $447 \mathrm{~cm}^{-1}$, due to the stretching of tetrahedral Fe-O [29]. The splitting of the intense band near $600 \mathrm{~cm}^{-1}$ in two bands (approximately 590 and $640 \mathrm{~cm}^{-1}$ ) is an effect of the finite size that causes the split of the vibrational energy levels in the nanoparticles [30]. Two other bands were observed: one centered near $3445 \mathrm{~cm}^{-1}$, attributed to the $\mathrm{O}-\mathrm{H}$ stretching both in hydroxyl groups on the MNPs surface and in adsorbed water molecules, and the other around $1640 \mathrm{~cm}^{-1}$ is attributed to the bending in these molecules [30,31]. Upon functionalization with oleic acid, the spectra of all MNPs show changes, indicating the presence of the fatty acid, nevertheless, in some samples (MNPs obtained by Methods \#1 and \#2), a band at $1720 \mathrm{~cm}^{-1}$ was still visible, probably due to the presence of unbound oleic acid molecules, forming a second layer [30]. The effect of the addition of propolis extract on the FTIR spectra was mainly related to the aromatic compounds.

The dependence of the method of production of MNPs as well as the strain on the impact of the adherence ability of microorganisms observed in the present work was also reported by some authors [16,32], using other strains and methods of production of NPs. The different response of diverse strains to the same compound or extract is expectable since there are not universal antimicrobials. However in the presence of functionalized nanoparticles with the same compound or extract, care must be taken in the production of such NPs, because unexpected activities may occur.

Recently, some works have demonstrated the capacity of propolis extract to prevent the adherence of several microorganisms (Streptococcus mutans, and several Staphylococcus aureus clinical strains) on abiotic (smooth glass or microplate) and biotic (HEp-2 (Human Epithelioma) and HeLa (cervical carcinoma)) surfaces [33-35]. With the exception of Veloz et al. [34], in the remaining works, the authors did not describe the chemical composition of propolis extracts; only refer the importance of phenol content on the inhibition of biofilm formation [33], or there is not ever any reference to the composition of the propolis sample [35].

The anti-MRSA activity of propolis extracts from different origins and consequently with distinct chemical compositions has been reported, as can be seen in Table 1, nevertheless the anti-MRSA biofilm formation by propolis is very scarcely reported or even absent, as far as we know. The capacity for inhibiting the growth of MRSA by propolis extracts has been attributed to several compounds, including phenolic esters (benzyl caffeate) and flavonoids (pinocembrin, galangin and their derivatives), also detected in our sample, nevertheless it also presents isocupressic acid, a diterpene, in relative high amounts; which along with the other phenols may be responsible for the anti-adherence activity found.

It is noteworthy to refer some discrepancies on the anti-MRSA activities of some components present in propolis and found in different works developed by diverse authors. As examples: Boisard et al. [17] found that the flavonoids pinobanksin-3-acetate, pinocembrin, chrysin, and galangin did not show anti-MRSA activity, in contrast to the prenyl caffeate. Nevertheless, the activities of the extracts were higher than the isolated compounds, which evidence a synergetic activity among the compounds present in the extracts. These results disagree with those found by Darwish et al. [20] and Pepeljnjak and Kosalec [23]. These authors reported higher activity of pinobanksin-3-acetate, pinocembrin and galangin than crude extracts.

Functionalized $\mathrm{Fe}_{3} \mathrm{O}_{4} / \mathrm{C}_{18}$ nanoparticles without propolis extract present ability for inhibiting the adherence of MRSA strains, as already reported by Anghel et al. [15], nevertheless always inferior when compared to those samples also functionalized with propolis extract, which reveals the importance of this extract on the activity.

\section{Materials and Methods}

\subsection{Chemicals and Reagents}

Hydrochloric acid $(\mathrm{HCl})$ and L-(+)-Ascorbic acid were purchased from Merck (Darmstadt, Germany). $\mathrm{Na}_{2} \mathrm{CO}_{3}$ and $\mathrm{Na}_{2} \mathrm{SO}_{3}$ were purchased from Riedel de Haen (Seelze, Germany). Chloroform 
$\left(\mathrm{CHCl}_{3}\right)$ was purchased from LAB-SCAN (Dublin, Ireland). Oleic acid and Iron(II) sulfate heptahydrate $\left(\mathrm{FeSO}_{4} \cdot 7 \mathrm{H}_{2} \mathrm{O}\right.$ ) were purchased from Sigma Aldrich (Steinheim, Germany). Iron(III) chloride anhydrous was purchased from Fluka Chemicals (Buchs, Switzerland). $\mathrm{NaOH}$ was from Pronalab (Madalena, Portugal). Ethanol was from Panreac Quimica (Barcelona, Spain). The medium brain-heart infusion (BHI) and Bacteriological agar type E were purchased from Biokar Diagnostics (Beauvais, France).

\subsection{Propolis Extract}

One gram of propolis from Morocco (region of Fez-Boulmane) was chopped into small pieces and extracted by maceration using $30 \mathrm{~mL}$ of $70 \%$ ethanol and maintained for one week at $37^{\circ} \mathrm{C}$ under agitation (200 rpm). The resulting solution was filtered under vacuum. A clear solution, without further purification, was used for successive analyses.

\subsection{GC-MS Analysis of Propolis Extract}

The analysis was performed with a Hewlett-Packard gas chromatograph 5890 series II Plus linked to a Hewlett-Packard 5972 mass spectrometer (Hewlett-Packard, Wilmington, DE, USA) system equipped with a $30 \mathrm{~m}$ long, $0.25 \mathrm{~mm}$ i.d., and $0.5 \mu \mathrm{m}$ film thickness HP5-MS capillary column. The work conditions were the same as previously reported [25]. Semi-quantification was carried out by internal normalization with the area of each compound. The addition of individual areas of the compounds corresponds to $100 \%$ area. Compound identification was performed using commercial libraries and comparison of mass spectra and retention times of reference compounds.

\subsection{Preparation of Magnetite Nanoparticles}

Magnetite nanoparticles were synthesized by three different methods.

\subsubsection{Method \#1}

The alkaline co-precipitation of iron salts in aqueous solutions, as described by Kang et al. [36], with some modifications, was as follows: $0.43 \mathrm{~mL}$ of $\mathrm{HCl} 12 \mathrm{M}$ was diluted with $12.5 \mathrm{~mL}$ of distilled water, and then $2.6 \mathrm{~g}$ of $\mathrm{FeCl}_{3}$ and $2.4 \mathrm{~g}$ of $\mathrm{FeSO}_{4} \cdot 7 \mathrm{H}_{2} \mathrm{O}(2: 1$ molar ratio) were both added under continuous magnetic stirring. The resulting solution was poured into $125 \mathrm{~mL}$ of $\mathrm{NaOH}(1.5 \mathrm{M})$ under vigorous stirring, which was maintained for $30 \mathrm{~min}$. The last step generated an instant black precipitate. The magnetism was checked with a NdFeB permanent magnet. The precipitate was attracted by the magnetic field, and the supernatant was removed by decantation. The recovered magnetite was washed with distilled water for three times and then twice with ethanol. The product was air-dried overnight and grinded into powder.

\subsubsection{Method \#2}

The co-precipitation, according to the procedure of Qu et al. [37] slightly modified, was as follows: $30 \mathrm{~mL}$ of a $2 \mathrm{M} \mathrm{FeCl}_{3}$ stock solution, prepared by dissolving the necessary amount of iron salt in $2 \mathrm{M} \mathrm{HCl}$, were diluted with an equal volume of deionized water. Afterwards, $20 \mathrm{~mL}$ of a $1 \mathrm{M} \mathrm{Na}_{2} \mathrm{SO}_{3}$ solution were added under stirring. Just after the mixing of $\mathrm{Fe}^{3+}$ and $\mathrm{SO}_{3}{ }^{2-}$, the color of the solution altered from light yellow to red, indicating the formation of a complex ion. Meanwhile, an ammonia solution was prepared by the dilution of $50.8 \mathrm{~mL}$ of concentrated ammonia to a final volume of $800 \mathrm{~mL}$. The former solution was quickly poured into the diluted ammonia solution, under vigorous stirring, as soon as its color changed back from red to yellow again, as the complex decomposed to $\mathrm{Fe}^{2+}$ and $\mathrm{SO}_{4}{ }^{2-}$. A black precipitate formed immediately, but stirring was continued for $30 \mathrm{~min}$. A permanent magnet was applied to the beaker containing the suspension, and a black powder could be seen to quickly settle on the bottom. The supernatant was discarded and fresh water was added to the beaker. After decantation, the powder was washed one time with an acidic solution ( $\mathrm{pH} 3-4)$, then with distilled water until neutral $\mathrm{pH}$, once with ethanol, and finally left to air dry overnight. 


\subsubsection{Method \#3}

Water-soluble magnetite nanoparticles were obtained by a hydrothermal method, according to Xuan et al. [38], using a ferric salt as single iron precursor, and ascorbic acid as reducing agent. The so synthesized super paramagnetic $\mathrm{Fe}_{3} \mathrm{O}_{4}$ nanocrystals are capped with dehydroascorbic acid (the oxidized form of ascorbic acid). In a typical experiment, $0.33 \mathrm{~g}$ of $\mathrm{FeCl}_{3}$ were dissolved in $25 \mathrm{~mL}$ of $\mathrm{H}_{2} \mathrm{O}$, under continuous stirring. Then, $10 \mathrm{~mL}$ of $0.6 \mathrm{M} \mathrm{Na}_{2} \mathrm{CO}_{3}(0.6 \mathrm{M})$ were added, drop by drop and, $10 \mathrm{~min}$ later, $0.12 \mathrm{~g}$ ascorbic acid were also added. After being stirred for another $15 \mathrm{~min}$, the solution was transferred to a $40 \mathrm{~mL}$ Teflon sealed autoclave. The autoclave was kept at $160{ }^{\circ} \mathrm{C}$ for $3 \mathrm{~h}$ and then let cool down to room temperature. The final product was separated from the reaction medium by using a $\mathrm{NdFeB}$ permanent magnet. A rinsing process including three cycles of decantation/washing/decantation in deionized water and in alcohol was performed before air drying overnight.

\subsection{Preparation of Functionalized Magnetite Nanoparticles}

Each magnetite type was functionalized with $6 \mathrm{~mL}$ of oleic acid (OA), the mixture being heated up to $80^{\circ} \mathrm{C}$ on a water bath, under intense stirring for $60 \mathrm{~min}$. Excess oleic acid was phase separated by dropwise addition of $4 \mathrm{~mL}$ of water, followed by OA-coated magnetite washing twice with ethanol and kept to dry overnight [39].

\subsection{Synthesis of A Hybrid Core/Shell/Coated Shell Nanomaterial}

Functionalized magnetite was added into $10 \mathrm{~mL}$ of $\mathrm{CHCl}_{3}(0.33 \% w / v)$ and was sonicated for $30 \mathrm{~min}$. One $\mathrm{mL}$ of propolis sample at the MIC value $(0.36 \mathrm{mg} / \mathrm{mL})$ was added into the same volume of the magnetite suspension.

\subsection{Characterization of the Nanomaterial}

Characterization of the nanomaterial was carried out by X-ray powder diffraction (XRD), transmission electron microscopy (TEM) (Hitachi High-Technologies Corporation, Tokyo, Japan), ${ }^{57} \mathrm{Fe}$ Mossbauer spectroscopy, and Fourier Transform Infrared (FTIR) spectroscopy (Bruker Tensor 27, Billerica, MA, USA).

\subsubsection{XRD}

The structure type of all the samples was checked by powder X-ray diffraction on a PANalytical $X^{\prime}$ Pert Pro diffractometer (PANalitycal, Almelo, The Netherlands) using $\mathrm{Cu}$ Ka radiation filtered by Ni and an $X^{\prime}$ Celerator detector. The equipment was operated at $45 \mathrm{kV}$ and $30 \mathrm{~mA}$ and the patterns were recorded in the range $20-80^{\circ} 2 \theta$, with a step size of $0.05^{\circ}$ and 1500 seconds per step and compared with the ICDD PDF-2 database.

\subsubsection{TEM}

Samples were prepared by drop drying a diluted colloidal solution of NPs in ethanol onto 200 mesh Formvar-coated copper grids. Samples were observed using a Hitachi 8100 (Hitachi High-Technologies Corporation), 200 kV, LaB6 filament analytical transmission electron microscope.

\subsubsection{Mossbauer Spectroscopy}

${ }^{57} \mathrm{Fe}$ Mossbauer spectroscopy was performed at room temperature on a Wissel constant acceleration transmission mode spectrometer (Wissenschaftliche Elektronik (WissEl) GmbH, Starnberg, Germany), using a proportional counter as detector and a ${ }^{57} \mathrm{Co} / \mathrm{Rh}$ source. The resulting spectra were calibrated with an $\alpha$-Fe foil and WMOSS software [40] was used for the quantitative evaluation of the spectral parameters (least-squares fitting to Lorentzian peaks). All isomeric shifts are reported relative to the centroid of the $\alpha$-Fe spectrum. 


\subsubsection{FTIR}

Infrared spectra were recorded in the wave numbers range $4000-400 \mathrm{~cm}^{-1}$, in a Bruker Tensor 27 Fourier-transform infrared (FT-IR) spectrophotometer (Bruker Tensor 27, Billerica, MA, USA), using KBr wafers.

\subsection{Impact of the Nanoparticles on Bacterial Adherence}

Catheter pieces treated with functionalized magnetite and propolis were filled with $100 \mu \mathrm{L}$ of an overnight bacterial culture MSSA ATCC 6538, MRSA 2, MRSA 15 and MRSA 16 (Table 3). The bacterial strains were cultivated in Brain Heart Infusion (BHI). For solid media, agar (VWR) was added at $1.5 \%, w / v$. Bacteria were maintained in BHI with $25 \%(v / v)$ glycerol at $-80{ }^{\circ} \mathrm{C}$ and, when necessary were recovered in BHI. Prior to use, bacteria were transferred to fresh $\mathrm{BHI}$ agar plates and incubated at $37^{\circ} \mathrm{C}$.

Table 3. Staphylococcus aureus strains.

\begin{tabular}{ccc}
\hline Bacteria & Origin & Source \\
\hline Staphylococcus aureus ATCC 6538 (MSSA ATCC 6538) & Wound & American Type Culture Collection \\
Staphylococcus aureus methicillin-resistant 2 (MRSA 2) & Clinical & UAlg, CBMR. Portugal \\
Staphylococcus aureus methicillin-resistant 15 (MRSA 15) & Clinical & UAlg, CBMR. Portugal \\
Staphylococcus aureus methicillin-resistant 16 (MRSA 16) & Clinical & UAlg, CBMR. Portugal \\
\hline
\end{tabular}

The previously obtained suspension of the nanomaterial was used to fabricate a modified surface in a prosthetic device. This was achieved by submerging the catheter pieces into the fluid in order to create a coating film. The catheter pieces were then dried at room temperature. This process of submerging and drying was repeated for five times of $10 \mathrm{~s}$ each, and the catheter pieces were sterilized by ultraviolet radiation for $20 \mathrm{~min}$.

Catheter pieces treated with functionalized magnetite were filled with $100 \mu \mathrm{L}$ of an overnight bacterial culture and left to adhere for $30 \mathrm{~min}$ at room temperature in a flow cabinet (Faster BH-EN 2005, Milan, Italy). Following the catheter pieces were transferred to Falcon tubes with $10 \mathrm{~mL}$ of Brain Heart Infusion (BHI) (Oxoid). Each tube was sonicated in a bath sonicator (J.P.SELECTA, Barcelona, Spain) for $5 \mathrm{~min}$, and the catheter was immediately removed. The bacterial suspension was serially diluted using phosphate buffer saline (PBS) and the viability was determined according to the Miles and Misra technique [41]. Catheters treated with non-functionalized magnetite and catheters not treated with magnetite were used as control [12].

\subsection{Statistical Analysis}

For the statistical interpretation GraphPad Prism statistical software was used, version 5.03 (GraphPad Software, La Jolla, CA, USA). The average of six independent experiments were analyzed and compared with one-way ANOVA using Tukey's Multiple Comparison Test of each group, followed by two-way ANOVA test for revealing significant differences among the analyzed group. Significant differences were indicated by $p$ values less than 0.05 .

\section{Conclusions}

The capacity of functionalized MNPs for preventing the adherence of $S$. aureus to catheters was dependent on two factors: the bacterial strain and the mode of production of the NPs. The MSSA ATCC 6538 strain was less affected by the presence of the functionalized MNPs, independently on the type of production, in contrast to the MRSA strains. For MRSA strains, the MNPs produced using $\mathrm{Fe}^{3+}$ and $\mathrm{Na}_{2} \mathrm{SO}_{3}$ solution and functionalized with oleic acid and propolis extract was most effective in the prevention of adherence of almost all MRSA strains on catheters. The hybrid MNPs produced by a hydrothermal method also had an impact in the impaired of the adherence of the strain MRSA16 
on catheters. The anti-MRSA activities reported for phenolic esters (benzyl caffeate) and flavonoids (pinocembrin, galangin and their derivatives), constituents of several types of propolis and also present in our sample can be the reason, along with MNPs, for the observed activities. However, the main compound, isocupressic acid, may also have a role in the anti-adherence activities detected, although to the best of our knowledge no reference has been found upon its anti-MRSA potential. In addition, for MRSA16, the impairment of its adherence on catheters may only be attributed to the hybrid MNPs with oleic acid, since very small amount, if any at all, of propolis compounds were added to the MNPs, according to the FTIR spectra.

Nanotechnology may provide a new approach to prevent or disrupt the formation of biofilms on medical devices. The association of natural products, such as propolis, with nanotechnology may constitute an alternative to combat the formation of those biofilm in catheters by MRSA strains.

Acknowledgments: Financial support through Fundação para a Ciência e a Tecnologia (FCT) within the projects UID/QUI/00100/2013, UID/BIM/04773/2013 CBMR and PEst-OE/QUI/UI4023/2011 is acknowledged.

Author Contributions: Maria G. Miguel and Maria L. Faleiro conceived and designed the experiments; Soukaïna El-Guendoz, Vassya Bankova, João P. Lourenço, Ana M. Rosa Costa, and José F. Mariano performed the experiments; all authors analyzed the data; and Maria G. Miguel, Maria L. Faleiro, João P. Lourenço, Ana M. Rosa Costa, José F. Mariano, and Soukaïna El-Guendoz wrote the paper.

Conflicts of Interest: The authors declare no conflict of interest.

\section{References}

1. Burdock, G.A. Review of the biological properties and toxicity of bee propolis (propolis). Food Chem. Toxicol. 1998, 36, 347-363. [CrossRef]

2. Barlak, Y.; Deger, O.; Çolak, M.; Karatayh, S.C.; Bozdayi, A.M.; Yücesan, F. Effect of Turkish propolis extracts on proteome of prostate cancer cell line. Proteome Sci. 2011, 9. [CrossRef] [PubMed]

3. Sforcin, J.M. Biological properties and therapeutic applications of propolis. Phytother. Res. 2016, 30, 894-905. [CrossRef] [PubMed]

4. Wertheim, H.F.L.; Vos, M.C.; Ott, A.; van Belkum, A.; Voss, A.; Kluytmans, J.A.J.W.; van Keulen, P.H.J.; Vandenbroucke, C.M.J.E.; Meester, M.H.M.; Verbrugh, H.A. Risk and outcome of nosocomial Staphylococcus aureus bacteraemia in nasal carriers versus non-carriers. Lancet 2004, 364, 703-705. [CrossRef]

5. Rybak, M.J.; LaPlante, K.L. Community-associated methicillin-resistant Staphylococcus aureus: A review. Pharmacotherapy 2005, 25, 74-85. [CrossRef] [PubMed]

6. Frank, D.N.; Feazel, L.M.; Bessesen, M.T.; Price, C.S.; Janoff, E.N.; Pace, N.R. The human nasal microbiota and Staphylococcus aureus carriage. PLoS ONE 2014, 5, e10598. [CrossRef] [PubMed]

7. Chambers, H.F.; DeLeo, F.R. Waves of resistance: Staphylococcus aureus in the antibiotic era. Nat. Rev. Microbiol. 2009, 7, 629-641. [CrossRef] [PubMed]

8. Huang, C.M.; Chen, C.H.; Pornpattananangkul, D.; Zhang, L.; Chan, M.; Hsieh, M.F.; Zhang, L. Eradication of drug resistant Staphylococcus aureus by liposomal oleic acids. Biomaterials 2011, 32, 214-221. [CrossRef] [PubMed]

9. Magana, M.; Ioannidis, A.; Magiorkinis, E.; Ursu, O.; Bologa, C.G.; Chatzipanagiotou, S.; Hamblin, M.R.; Tegos, G.P. Therapeutic options and emerging alternatives for multidrug resistant Staphylococcus infections. Curr. Pharm. Des. 2015, 21, 2058-2072. [CrossRef] [PubMed]

10. Wojtyczka, R.D.; Dziedzic, A.; Idzik, D.; Kepa, M.; Kubina, R.; Kabala-Dzik, A.; Smolén-Dzirba, J.; Stjko, J.; Sajewicz, M.; Wasik, T.J. Susceptibility of Staphylococcus aureus clinical isolates to propolis extract alone or in combination with antimicrobial drugs. Molecules 2013, 18, 9623-9640. [CrossRef] [PubMed]

11. Cartelle, G.M.; Holban, A.M. Advances in nanotechnology as an alternative against superbags. JSM Chem. 2014, 2, 1011.

12. Chifiriuc, C.; Grumezescu, V.; Grumezescu, A.M.; Saviuc, C.; Lazăr, V.; Andronescu, E. Hybrid magnetite nanoparticles/Rosmarinus officinalis essential oil nanobiosystem with antibiofilm activity. Nanoscale Res. Lett. 2012, 7. [CrossRef] [PubMed]

13. Liakos, I.; Grumezescu, A.M.; Holban, A.M. Magnetite nanostructures as novel strategies for anti-infections therapy. Molecules 2014, 19, 12710-12726. [CrossRef] [PubMed] 
14. Wu, W.; He, Q.; Jiang, C. Magnetic iron oxide nanoparticles: Synthesis and surface functionalization strategies. Nanoscale Res. Lett. 2008, 3, 397-415. [CrossRef] [PubMed]

15. Anghel, I.; Grumezescu, A.M.; Andronescu, E.; Anghel, A.G.; Ficai, A.; Saviuc, C.; Grumezescu, V.; Vasile, B.S.; Chifiriuc, M.C. Magnetite nanoparticles for functionalized textile dressing to prevent fungal biofilms development. Nanoscale Res. Lett. 2012, 7, 501. [CrossRef] [PubMed]

16. Poiată, A.; Tuchilus, C.; Creangă, D.; Stan, C. Magnetic nanoparticles influence on some bacterial cultures. Rom. J. Biophys. 2013, 23, 203-209.

17. Boisard, S.; Le Ray, A.M.; Landreau, A.; Kempf, M.; Cassisa, V.; Flurin, C.; Richomme, P. Antifungal and antibacterial metabolites from a French poplar type propolis. Evid. Based Complement. Altern. Med. 2015, 2015. [CrossRef] [PubMed]

18. Astani, A.; Zimmermann, S.; Hassan, E.; Reichling, J.; Sensch, K.H.; Schnitzler, P. Antimicrobial activity of propolis special extract GH2002 against multidrug-resistant clinical isolates. Pharmazie 2013, 68, 695-701. [PubMed]

19. Pamplona-Zomenhan, L.C.; Pamplona, B.C.; Silva, C.B.; Marcucci, M.C.; Mímica, L.M.J. Evaluation of the in vitro antimicrobial activity of an ethanol extract of Brazilian classified propolis on strains of Staphylococcus aureus. Braz. J. Microbiol. 2011, 42, 1259-1264. [PubMed]

20. Darwish, R.M.; Fares, R.J.A.; Zarga, M.H.A.; Nazer, I.K. Antibacterial effect of Jordanian propolis and isolated flavonoids against human pathogenic bacteria. Afr. J. Bacteriol. 2010, 9, 5966-5974.

21. Raghukumar, R.; Vali, L.; Watson, D.; Fearnley, J.; Seidel, V. Antimethicillin-resistant Staphlylococcus aureus (MRSA) activity of 'Pacific propolis' and isolated prenylflavanones. Phytother. Res. 2010, 24, 1181-1187. [PubMed]

22. Onlen, Y.; Duran, N.; Atik, E.; Savas, L.; Altug, E.; Yakan, S.; Aslantas, O. Antibacterial activity of propolis against MRSA and synergism with topical mupirocin. J. Altern. Complement. Med. 2007, 13, 713-718. [CrossRef] [PubMed]

23. Pepeljnjak, S.; Kosalec, I. Galangin expresses bactericidal activity against multiple-resistant bactéria: MRSA, Enterococcus spp. and Pseudomonas aeruginosa. FEMS Microbiol. Lett. 2004, 240, 111-116. [CrossRef] [PubMed]

24. Huang, S.; Zhang, C.P.; Wang, K.; Li, G.Q.; Hu, F.L. Recent advances in the chemical composition of propolis. Molecules 2014, 19, 19610-19632. [CrossRef] [PubMed]

25. Popova, M.; Lyoussi, B.; Aazza, S.; Antunes, D.; Bankova, V.; Miguel, G. Antioxidant and $\alpha$-glucosidase inhibitory properties and chemical profiles of Moroccan propolis. Nat. Prod. Commun. 2015, 10, 1961-1964. [PubMed]

26. Paramês, M.L.; Mariano, J.; Viskadourakis, Z.; Popovici, N.; Rogalski, M.S.; Giapintzakis, J.; Conde, O. PLD of $\mathrm{Fe}_{3} \mathrm{O}_{4}$ thin films: Influence of background gas on surface morphology and magnetic properties. Appl. Surf. Sci. 2006, 252, 4610-4614. [CrossRef]

27. Mahdavi, M.; Ahmad, M.B.; Haron, M.J.; Namvar, F.; Nadi, B.; Rahman, M.Z.A.; Amin, J. Synthesis, surface modification and characterisation of biocompatible magnetic iron oxide nanoparticles for biomedical applications. Molecules 2013, 18, 7533-7548. [CrossRef] [PubMed]

28. Lawaczeck, R.; Menzel, M.; Pietsch, H. Superparamagnetic iron oxide particles: Contrast media for magnetic resonance imaging. Appl. Organomet. Chem. 2004, 18, 506-513. [CrossRef]

29. Casillas, P.E.G.; Gonzalez, C.A.R.; Pérez, C.A.M. Infrared spectroscopy of functionalized magnetic nanoparticles. In Infrared Spectroscopy-Materials Science, Engineering and Technology; Theophanides, T., Ed.; InTech: Rijeka, Croatia, 2012; pp. 405-420.

30. Yang, K.; Peng, H.; Wen, Y.; Li, N. Re-examination of characteristic FTIR spectrum of secondary layer in bilayer oleic acid-coated $\mathrm{Fe}_{3} \mathrm{O}_{4}$ nanoparticles. Appl. Surf. Sci. 2010, 256, 3093-3097. [CrossRef]

31. Ma, M.; Zhang, Y.; Yu, W.; Shen, H-y.; Zhang, H-q.; Gu, N. Preparation and characterization of magnetite nanoparticles coated by amino silane. Colloids Surf. A Physicochem. Eng. Asp. 2003, 212, 219-226. [CrossRef]

32. Chifiriuc, C.; Lazăr, V.; Bleotu, C.; Călugărescu, I.; Grumezescu, A.M.; Mihaiescu, D.E.; Mogosanu, D.E.; Buteică, A.S.; Buteică, E. Bacterial adherence to the cellular and inert substrate in the presence of $\mathrm{CoFe}_{2} \mathrm{O}_{4}$ and $\mathrm{Fe}_{3} \mathrm{O}_{4}$ /oleic acid-core/shell. Dig. J. Nanomater. Biostruct. 2011, 6, 37-42.

33. Asawahame, C.; Sutjarittangtham, K.; Eitssayeam, S.; Tragoolpua, Y.; Sirithunyalug, B.; Sirithunyalug, J. Antibacterial activity and inhibition of adherence of Streptococcus mutans by propolis electrospun fibers. AAPS PharmSciTech 2015, 16, 182-191. [CrossRef] [PubMed] 
34. Veloz, J.J.; Saavedra, N.; Lillo, A.; Alvear, M.; Barrientos, L.; Salazar, L.A. Antibiofilm activity of Chilean propolis on Streptococcus mutans is influenced by the year of collection. BioMed Res. Int. 2015, 2015. [CrossRef] [PubMed]

35. Stan, T.; Mărutescu, L.; Chifiriuc, M.C.; Lazăr, V. Anti-pathogenic effect of propolis extracts from different Romanian regions on Staphylococcus sp. Clinical strains. Rom. Biotechnol. Lett. 2016, 21, 11166-11175.

36. Kang, Y.S.; Rabolt, J.F.; Risbud, S.; Stroeve, P. Synthesis and characterization of nanometer-size $\mathrm{Fe}_{3} \mathrm{O}_{4}$ and $\gamma-\mathrm{Fe}_{2} \mathrm{O}_{3}$ particles. Chem. Mater. 1996, 8, 2209-2211. [CrossRef]

37. Qu, S.; Yang, H.; Ren, D.; Kan, S.; Zou, G.; Li, D. Magnetite nanoparticles prepared by precipitation from partially reduced ferric chloride aqueous solutions. J. Colloid Interface Sci. 1999, 215, 190-192. [CrossRef] [PubMed]

38. Xuan, S.; Hao, L.; Jiang, W.; Gong, X.; Hu, Y.; Chen, Z. Preparation of water-soluble magnetite nanocrystals through hydrothermal approach. J. Magn. Magn. Mater. 2007, 308, 210-213. [CrossRef]

39. Foca-nici; Ciurlica, E.L.; Nadejde, C.; Creanga, D.E.; Carlescu, A.; Badescu, V. Antibiotic Coated Magnetite Nanoparticles for Biological Applications. Available online: http://www.jscimedcentral.com/Chemistry/ chemistry-2-1011.pdf (accessed on 3 April 2016).

40. Prisecaru, I. WMOSS4 Mössbauer Spectral Analysis Software. 2016. Available online: http:/ /www.wmoss. org (accessed on 5 February 2016).

41. Miles, A.A.; Misra, S.S. The estimation of the bactericidal power of blood. J. Hyg. (London) 1938, 38, 732-749. [CrossRef]

Sample Availability: Samples of the compounds from the authors are not available.

(C) 2016 by the authors; licensee MDPI, Basel, Switzerland. This article is an open access article distributed under the terms and conditions of the Creative Commons Attribution (CC-BY) license (http:/ / creativecommons.org/licenses/by/4.0/). 